\title{
Modeling and Simulation of Certain Type Turret Based on Finite Element Method
}

\author{
Jinzhong Zhang, Xiaofeng Liu*, Fuquan Zhao and Yuchen Yue \\ Department of Arms Engineering, Academy of Armored Force Engineering, Beijing ,China \\ ${ }^{*}$ Corresponding author
}

\begin{abstract}
The turret is subjected to a huge impact load during the firing of the gun. Therefore, the stiffness of the structure of the turret body in the launching state is the key problem to be considered in the design. In this paper, based on the turret model of a certain infantry combat vehicle, the modal analysis of the turret is carried out by using the finite element method. The natural frequencies and modes of the turret are obtained. On this basis, studied the stress and deformation of the turret under the launching load. The results show that the vibration of the turret structure accords with the vibration characteristics of the shell structure, but exhibits the local vibration characteristics. The maximum equivalent stress of the turret is distributed near the trunnion of the bracket during the firing process.
\end{abstract}

Keywords-turret; finite element method; modal analysis; modeling and simulation

\section{INTRODUCTION}

Tracked infantry combat vehicle gun system is a modern artillery system with a high mobility performance of the artillery firing system. The turret structure is subjected to the recoil resistance and balance force during the gun firing process. These forces cause the brackets of the turret structure and the other connecting parts of the turret to generate stress. These stresses are the main factors to destroy the turret structure, and result in deformation of turret, so that influence the gun firing accuracy. Through the strength calculation of the turret structure, can test whether the turret has enough strength, can ensure that the gun in normal working conditions, the turret does not occur the phenomenon of damage in all parts, meanwhile can give advice for structural improvements, so that the deformation of the structure is reduced and the firing precision is improved[1].

In this paper, the modal of turret structure to be analyzed, and then the process of firing gun recoil as the dynamic load of the system to analyze the stress and deformation of the turret structure.

\section{THE EstABLishment OF Finite ELEMENT MODEL OF TURRET}

In this paper, the three-dimensional model of the turret of a certain type infantry combat vehicle is established by SOLIDWORKS. Then the three-dimensional model is saved as the intermediate format into the ANSYS for pre-processing, and a finite element model of the turret is established. Taking into the degree of difficulty and the amount of calculation ANSYS meshing consideration, deleted three-dimensional model chamfers, fillets and structure the calculation results not affect the firing accuracy, such as smoke launchers on both sides of the turret, periscope on top of the turret and the door of commander and gunner. The final three-dimensional model of the turret shown in Figure 1.

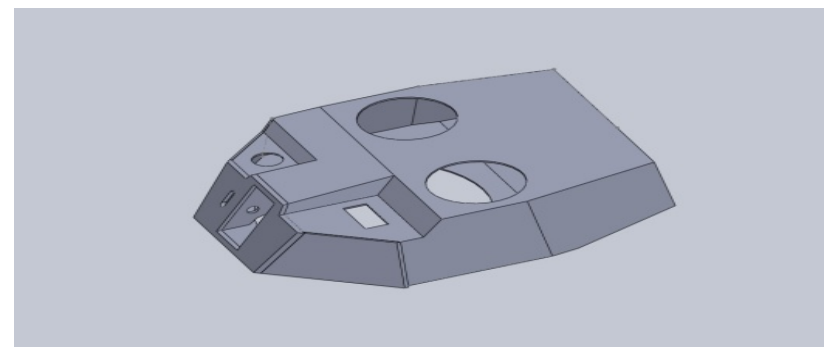

FIGURE I. THREE - DIMENSIONAL SOLID MODEL OF TURRET.

Importing the three-dimensional solid model of the turret into the software ANSYS, and meshing the model. In order to improve the accuracy of calculation and to facilitate the inverse mapping of the isoparametric elements, the front armour, the left and right armour are divided into hexahedral elements, the other parts are divided by tetrahedral elements, and mesh of the bracket trunnion hole supported recoil resistance to perform encryption processing[2]. The final finite element model of the turret is shown in Figure 2.

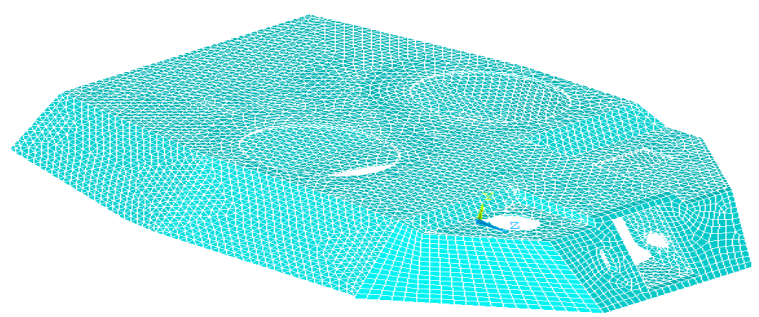

FIGURE II. FINITE ELEMENT MODEL OF TURRET

\section{ANALYSIS ON THE FORCE OF TURRET}

The type of infantry combat tanks equipped with largecaliber tank gun, in the firing moment, the gun has a greater recoil, recoil through the trunnion to the turret bracket, and then have a impact on the turret[3]. Therefore, in order to analyze the dynamic response of turret under the action of recoil, need take the theory of structural dynamics. According to the theory of structural dynamics, the equilibrium equation of the structure under dynamic load is: 


$$
M \ddot{x}(t)+C \dot{x}(t)+K x(t)=F(t)
$$

Equation (1): $\ddot{x}(t) \quad \dot{x}(t) \quad x(t) \quad$ corresponding to the acceleration vector, velocity vector and deflection vector of a point in the structure. $M, C, K$ corresponding mass matrix, damping matrix, stiffness matrix of the structure. $F(t)$ is dynamic load vector of structure.

ANSYS provides three methods to solve (1): complete method, reduction method and modal superposition method. Considering the computational cost, this paper adopts the modal superposition method with the highest computational efficiency. The modal superposition method is a method of calculating the response of a structure by the mode of vibration (eigenvalue) obtained by the modal analysis multiplied by the factors and the summation.

\section{MOdAl ANALYSIS OF TURRET}

ANSYS calculates the natural vibration characteristics of the structure by modal analysis. The purpose of this analysis is to determine the natural frequency of the structure. Modal analysis is the basis of other ANSYS dynamic analysis, such as dynamic analysis based on modal superposition, harmonic response analysis and response spectrum analysis. Before the dynamic analysis of turret was carried out by modal superposition method, modal analysis of the turret is required.

The first six natural frequency of turret by ANSYS software analysis as shown in Table 1, the first six modes shown in Figure 3.

\section{TABLE I. FIRST SIX NATURAL FREQUENCY OF TURRET}

\begin{tabular}{|c|c|c|c|c|c|c|}
\hline Modal & $\mathbf{1}$ & $\mathbf{2}$ & $\mathbf{3}$ & $\mathbf{4}$ & $\mathbf{5}$ & $\mathbf{6}$ \\
\hline $\begin{array}{c}\text { Frequency } \\
(\mathrm{Hz})\end{array}$ & 41.69 & 86.71 & 91.79 & 129.82 & 153.6 & 170.87 \\
\hline
\end{tabular}
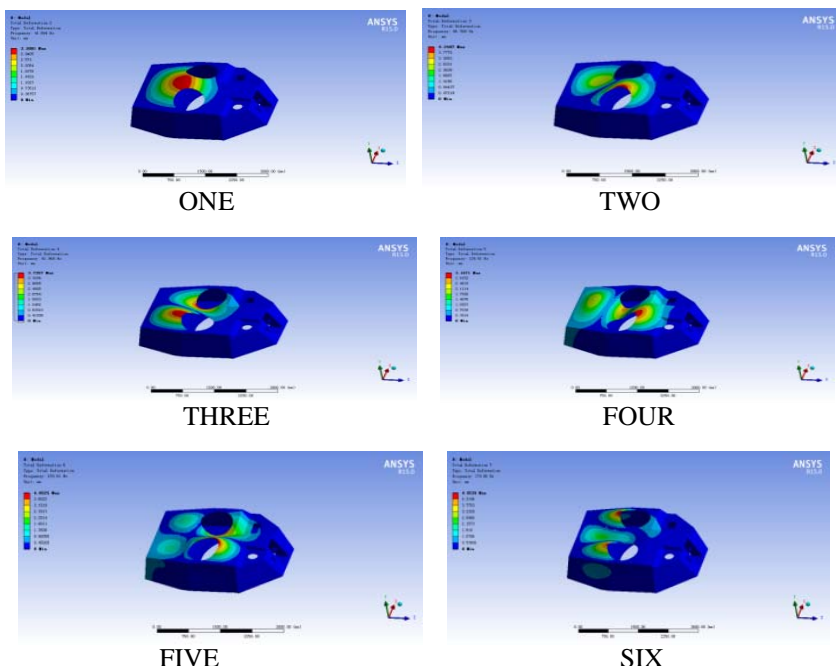

FIGURE III. FIRST SIX MODES OF TURRET

Through Figure 3 to see, the vibration of the turret structure accords with the vibration characteristics of the shell structure, but shows the local vibration characteristics. The larger deformation area is mainly near the door of commander and gunner which are located top of the turret, because there are more opened doors, resulting in insufficient overall stiffness, so the turret structure improvement should be added in the stiffener here to make up for lack of stiffness.

\section{DYNAMIC RESPONSE OF TURRET UNDER LAUNCHING}

The Artillery firing is a very complex process, the artillery recoil transmission to the trunnion hole, and in the recoil to start a very short period of time rapidly increased to a value, then until the projectile before the muzzle to maintain the value in the vicinity, at the end of the recoil rapidly decreased[4-5]. The dynamic response load condition of the turret is the calculated recoil resistance, and the curve is shown in Figure 4.

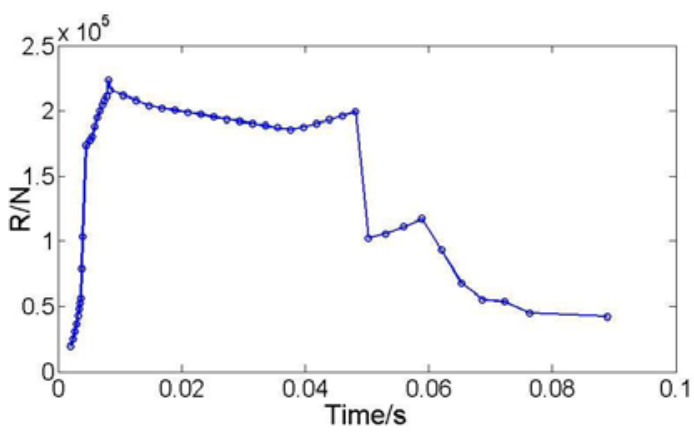

FIGURE IV. GUN RECOIL RESISTANCE CURVE

In the firing process, artillery recoil through the trunnion applied to half cylindrical surface part of bracket trunnion hole. It is assumed that the recoil resistance acts evenly on the bracket through the left and right trunnion bearings, usually, the force is distributed sinusoidally along the inner periphery of the trunnion bearing, and approximately evenly distributed along the bearing axis [6]. In this paper, the equivalent stress nephogram of the turret is obtained in 0.00821s and 0.05s. As shown in Figure 5 and Figure 6.

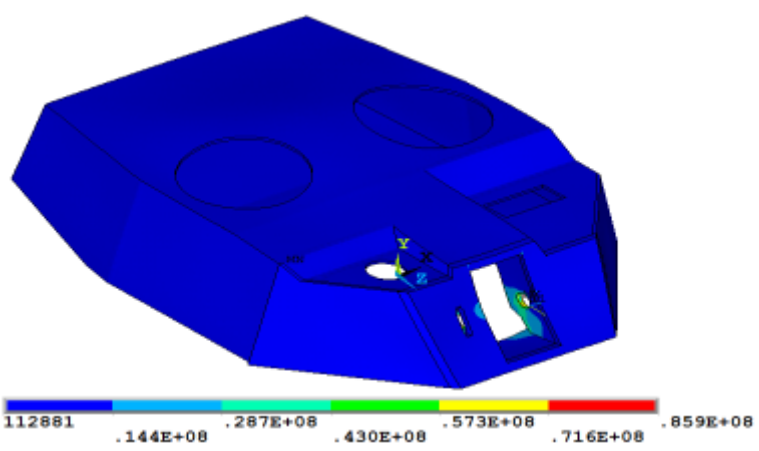

FIGURE V. THE EQUIVALENT STRESS NEPHOGRAM OF THE TURRET AT 0.00821S. 


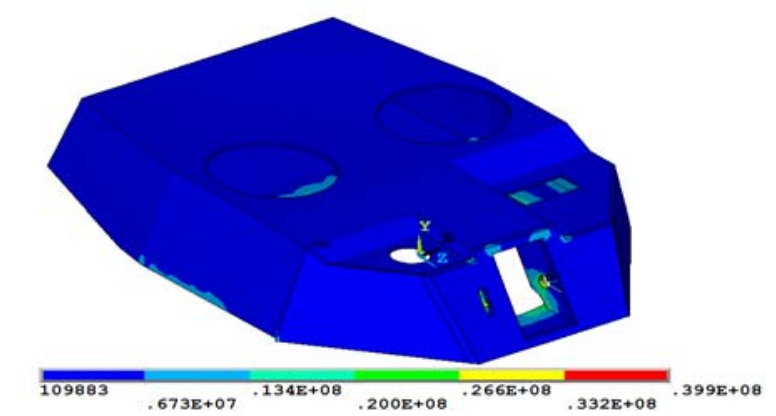

FIGURE VI. THE EQUIVALENT STRESS NEPHOGRAM OF THE TURRET AT 0.05S.

Figure 5 and Figure 6 are the equivalent stress nephogram of the turret at the critical time point in the gun firing process. It can be seen from Fig.5 and Fig.6 that the maximum equivalent stress of the turret is distributed in the vicinity of the trunnion hole of the bracket during the firing process of the gun, and its value changes with the change of the recoil resistance.

\section{CONCLUSION}

In this paper, by building a finite element model of the turret of a certain infantry combat vehicle, the modal analysis of the turret and the dynamic response analysis based on the firing load are made. And the results show that the vibration of the turret structure accords with the vibration characteristics of the shell structure, but exhibits the local vibration characteristics. The maximum equivalent stress of the turret is distributed near the trunnion of the bracket during the firing process.

\section{REFERENCES}

[1] CHEN Long-miao, QIAN Lin-fang. Transient Simulation Analysis for Turrent Launching Loads. Journal of Simulation, 2008(20):6557-6559.

[2] Liu Quansheng, Wang Shuaishuai, Gao yushui, Li Peifu. Vibration Simulation of Infantry Combat Vehicle Turret. Ordnance Industry Automation, 2012(12):93-96.

[3] HAN Xiao-ping, YANG Ming-hua, WANG Guo-gang, HAO Gang. Ransient Dynamics of Structural Analysis of Turrect-Type Infantry Fighting Vehicles. Journal of Sichuan Militray Science and Technology, 2015(7):24-27.

[4] DU Chun-jiang, QIAN Lin-fang, XU Ya-dong, CHEN Long-miao. Structural Analysis and Optimzation for Turrect Body. Journal of System Simulation, 2009(15):4899-4902.

[5] DU Chun-jiang, QIAN Lin-fang, CHEN Long-miao, XU Ya-dong. Topology Optimization of Turrect Body. Journal of Ballistics, 2009(4):103-106.

[6] ZHAO Fu-quan, ZHANG Yan-yan, ZHANG Jin-zhong. Load Coupling Analysis of Armored Vehicle Turrect During Firing. Computer Simulation, 2015(8):6-9. 